\title{
Enhancing the rational use of new medicines across European health care systems
}

\author{
Silvio Garattini • Vittorio Bertele' • Brian Godman • \\ Alan Haycox • Björn Wettermark • Lars L. Gustafsson • \\ The Piperska Group
}

Published online: 8 August 2008

(C) The Author(s) 2008

How do we maintain the ideals underlying socially funded and equal health services under demanding conditions of the twenty-first century? Expenditure on health care throughout Europe has been rising more rapidly than any other public service, and pharmaceutical expenditure more rapidly than other components of healthcare [1]. The reasons underlying this tendency are well known: demographic changes, rising patient expectations, stricter clinical targets, and expensive new technologies [2]. To what extent is such pressure compatible with the aim of financing a comprehensive and equitable health service in Europe that is largely free at the point of delivery? In addition, what can be done to address these pressures?

A two-day meeting involving 33 leading health care professionals from nine European Union (EU) countries

Piperska Group was created during a 2-day meeting in January 2008 in Stockholm - at Conference Hall Piperska Muren - a meeting centre for 300 years.

S. Garattini $\cdot$ V. Bertele' $\cdot$ B. Godman

"Mario Negri", Institute for Pharmacological Research,

Milano, Italy

\section{A. Haycox}

Management School, University of Liverpool,

Liverpool, England

\section{B. Wettermark • L. L. Gustafsson $(\bowtie)$}

Division of Clinical Pharmacology,

Department of Laboratory Medicine, Karolinska Institutet,

Stockholm, Sweden

e-mail: lars-1.gustafsson@ki.se

B. Wettermark · L. L. Gustafsson

Department of Drug Management and Informatics,

Stockholm County Council,

Stockholm, Sweden was recently convened in Stockholm to address these issues. A deliberate decision was made not to seek external funding in order to ensure a free exchange of ideas from independent academics, regulators, and clinicians. Each delegate is actively involved either in registration, reimbursement, formulary listing, and/ or enhancing the rational use of drugs in his or her country. The meeting was hosted by the Karolinska Institute and Stockholm County Council together with leaders from the 'Mario Negri' Institute of Pharmacological Research in Milan and the universities of Heidelberg, Liverpool, and Marseilles.

The meeting identified that optimizing the use of new expensive technologies represented the major challenge faced by health care services throughout Europe, especially with pharmaceutical companies seeking to overcome lost revenues from patent expiry estimated at over $\$ 100$ bn USD per year over the next 4 years [3]. Whereas increasing the proportion of health care expenditure allocated to drugs is not intrinsically regrettable, ongoing pressure reinforces the need to ensure optimum stewardship of national pharmaceutical expenditure. This was encapsulated in the agreed vision which was "to ensure robust systems are in place in Europe to enhance the rational use of drugs, including new, expensive drugs, to improve health." The delegates believed these objectives could be achieved by collaborating and developing pan-European strategies to shared problems and pressures that can be adapted locally.

Guidelines and incentives are seen as beneficial to enhance rational use in line with an approach that has became known as the "five E's," namely: Evaluation, Economics, Enforcement, Education, and Engineering. Rational use of new, expensive drugs would also be enhanced through obtaining greater transparency in the information provided by pharmaceutical companies to regulators and national reimbursement agencies $[4,5]$. Ensuring a basic infrastruc- 
ture is in place for early and ongoing assessment of the value of new drugs was also seen as a key step for the future. Developing common databases and registries among European countries to capture utilization, safety, and outcome data of new drugs and using such databases to assess their clinical effectiveness and cost-effectiveness in real-world practice would also be very beneficial to refine future guidance. Last, it was believed that independent panEuropean studies are essential to generate robust and reliable evidence to enhance the future rational use of new, expensive drugs, building on, for instance, the experience in Italy [6].

The Piperska group is developing a range of panEuropean collaborative work programs to pursue these objectives, which it aims to have funded and operational by 2010. Representatives from a "new" European country, Poland, emphasized the potential value of collaboration with "old" European countries to identify strategies and policies to better manage the development of their health care systems. Such collaboration between new and old Europe is at the heart of the work programs being developed.

The Piperska organizing committee on behalf of the Piperska group:

- Silvio Garattini, Institute for Pharmacological Research 'Mario Negri', Milan, Italy.

- Vittorio Bertele', Institute for Pharmacological Research 'Mario Negri', Milan, Italy.

- Brian Godman. Institute for Pharmacological Research 'Mario Negri', Milan, Italy, and University of Liverpool Management School, Liverpool, UK.

- Alan Haycox, University of Liverpool Management School, Liverpool, UK.
- Bjorn Wettermark, Division of Clinical Pharmacology, Department of Laboratory Medicine, Karolinska Institute, Sweden, and Department of Drug Management and Informatics, Stockholm County Council, Stockholm, Sweden.

- Lars L. Gustafsson (corresponding author), Division of Clinical Pharmacology, Department of Laboratory Medicine, Karolinska Institute, Sweden, and Department of Drug Management and Informatics, Stockholm County Council, Stockholm, Sweden.

Open Access This article is distributed under the terms of the Creative Commons Attribution Noncommercial License which permits any noncommercial use, distribution, and reproduction in any medium, provided the original author(s) and source are credited.

\section{References}

1. Garattini L, Motterlini N, Cornago D (2008) Prices and distribution margins of in-patent drugs in pharmacy: A comparison in seven European countries. Health Policy 85:305-813

2. Lee TH, Emanuel EJ (2008) Tier 4 drugs and the fraying of the social compact. New Engl J Medicine 359:333-335

3. Jack A (2008) Balancing big pharma's books. BMJ 336:418-419

4. Melander H, Ahlqvist-Rastad J, Meijer G, Beermann B (2003) Evidence b(i)ased medicine - selective reporting from studies sponsored by pharmaceutical industry: review of studies in new drug applications. BMJ 326:1171-1173

5. Chan A-W, Hróbjartsson A, Haaber M, Gøtzsche P, Altman D (2004) Empirical evidence for selective reporting of outcomes in randomised trials. JAMA 291:2457-2465

6. Garattini S, Bertele' V (2007) How can we regulate medicines better. BMJ 335:803-805 